\title{
Changing Trends of Types of Skin Cancer in Iran
}

\author{
Saeid Razi ${ }^{1}$, Hosein Rafiemanesh ${ }^{2}$, Mahshid Ghoncheh ${ }^{3}$, Yousef Khani ${ }^{4}$, Hamid \\ Salehiniya ${ }^{2,5 *}$
}

\begin{abstract}
Background: Skin cancer is the most common type of cancer worldwide. It has an increasing trend. This study investigated the epidemiological trend and morphological changes in skin cancer in Iran. Materials and Methods: This study was done using existing data, extracted from the National Cancer Registry System and the Disease Management Center of Iranian Ministry of Health between 2003 and 2008. Data on epidemiologic trend was analyzed using Joinpoint software package. Results: The incidence of skin cancer is increasing in Iran, and more in men than women. There was a declining trend for basal cell carcinoma. Basal squamous cell carcinoma and melanoma had an increasing trend. The increase of skin cancer was related to squamous cell carcinoma. Conclusions: Our findings indicated that the increase of skin cancer was attributed to squamous cell carcinoma. It is necessary to be planning for the control and prevention of this disease as a priority for health policy makers.
\end{abstract}

Keywords: Skin cancer - trend - morphology - incidence - Iran

Asian Pac J Cancer Prev, 16 (12), 4955-4958

\section{Introduction}

Skin cancer is one of the most common cancers worldwide (Cihan et al., 2013). It is observed as melanoma and non-melanoma (Baldwin and Dunn, 2013). The two most common types of non-melanoma cancer are basal cell carcinoma and squamous cell carcinoma (Cihan et al., 2013). The annual incidence of non-melanoma is 2 to 3 million cases, while At least 132,000 melanoma cases occur in the world (WHO, 2015). More than half of incidence cases of the cancer and two thirds of death occur in low- and middle-income countries (Rohani-Rasaf et al., 2013). It is estimated that cancer incidence will increase to $45 \%$ in developing countries by 2025 (Amoori et al., 2014; Keyghobadi et al., 2015).

The cancer incidence pattern is different in various geographical regions, mainly because of the differences in risk factor (Rohani-Rasaf et al., 2013; Almasi et al., 2015). These risk factors include physical factors (ionizing and non-ionizing radiation), chemical factors (smoking, alcohol, environmental pollution, occupational exposure), biological factors (cancer-causing infectious agents), and genetic factor (Jemal et al., 2010). Ultraviolet radiation is the most important risk factor. In addition to the beneficial effects of this radiation, without the use of protective equipment, it may cause serious injuries, including malignant melanoma which is the most invasive form of skin cancer associated with a high mortality (Saridi et al., 2014).

The increase in population, life expectancy, and the proportion of the elderly population, and socio-economic status and lifestyle changes causes to become Iran as the country at high risk of skin cancer (Parkin et al., 2005; Colditz et al., 2006; Keyghobadi et al., 2015). Although skin cancer is one of the most common cancers, it is one of the most preventable types of cancer. If the primary prevention begins at an earlier age, the effect will be greater (Reynolds et al., 2006). There is the high incidence of skin cancer in Iran. The lack of a comprehensive and systematic study on the morphology and clinical aspects of the disease in the country can be effective in planning and preventative measures for the cancer. This study investigated the epidemiological trend and morphological changes in skin cancer in Iran.

\section{Materials and Methods}

This is cross- sectional study in Iran. The data were collected from Cancer Registry Center report of health deputy which is based on Iran ministry of health guideline(Goya, 2007). Data were collected retrospectively reviewing all new skin cancer patients in cancer registry

${ }^{1}$ Reproductive Biotechnology Research Center, Avicenna Research Institute, Academic Center for Education, Culture and Research (ACECR), ${ }^{2}$ Department of Epidemiology and Biostatistics, School of Public Health, Tehran University of medical sciences, ${ }^{5}$ Minimally Invasive Surgery Research Center, Iran University of Medical Sciences, Tehran, ${ }^{3}$ Department of Epidemiology \& Biostatistics, School of Public Health, Hamadan University of Medical Sciences, Hamadan, ${ }^{4}$ Alborz. University of Medical Sciences, Karaj, Iran *For correspondence: alesaleh70@yahoo.com 
Table 1. Joinpoint analysis in Standardized Incidence Rate (per thousand) in Male and Female in 2003 and 2008

\begin{tabular}{|c|c|c|c|c|c|c|c|c|c|}
\hline & \multicolumn{3}{|c|}{ Full Range } & \multicolumn{3}{|c|}{ Trend 1} & \multicolumn{3}{|c|}{ Trend 2} \\
\hline & years & AAPC & $95 \% \mathrm{CI}$ & years & APC & $95 \% \mathrm{CI}$ & Years & APC & $95 \% \mathrm{CI}$ \\
\hline Male & $2003-2008$ & $9.3^{\wedge}$ & 5.0 to 13.7 & $2003-2005$ & 16.9 & -16.5 to 63.7 & $2005-2008$ & 5.0 & -11.3 to 24.3 \\
\hline Female & 2003- 2008 & $8.5^{\wedge}$ & 5.4 to 11.8 & & & & & & \\
\hline
\end{tabular}

$\wedge=\mathrm{APC}$ or AAPC is significantly different from zero at alpha $=0.05$

Table 2. Frequency and Percent Change in the Percentage Allocated to the Morphology Data for Skin Cancer (2008-2003)

\begin{tabular}{|c|c|c|c|c|c|c|c|c|c|c|c|c|}
\hline & \multicolumn{2}{|c|}{2003} & \multicolumn{2}{|c|}{2004} & \multicolumn{2}{|c|}{2005} & \multicolumn{2}{|c|}{2006} & \multicolumn{2}{|c|}{2007} & \multicolumn{2}{|c|}{2008} \\
\hline & $\mathrm{N}$ & $\%$ & $\mathrm{~N}$ & $\%$ & $\mathrm{~N}$ & $\%$ & $\mathrm{~N}$ & $\%$ & $\mathrm{~N}$ & $\%$ & $\mathrm{~N}$ & $\%$ \\
\hline \multicolumn{13}{|l|}{ Female } \\
\hline Basal Cell Carcinoma, Nos & 1743 & 75.91 & 2108 & 75.85 & 2232 & 70.59 & 2274 & 69.12 & 2266 & 66.59 & 2439 & 65.99 \\
\hline Squamous Cell Carcinoma, Nos & 282 & 12.28 & 351 & 12.63 & 450 & 14.23 & 440 & 13.37 & 477 & 14.02 & 469 & 12.69 \\
\hline Malignant Melanoma, Nos & 56 & 2.44 & 80 & 2.88 & 85 & 2.69 & 91 & 2.77 & 105 & 3.09 & 123 & 3.33 \\
\hline Basosquamous Carcinoma & 33 & 1.44 & 37 & 1.33 & 62 & 1.96 & 59 & 1.79 & 54 & 1.59 & 68 & 1.84 \\
\hline \multicolumn{13}{|l|}{ Male } \\
\hline Basal Cell Carcinoma, Nos & 2590 & 69.07 & 3084 & 67.91 & 3380 & 63.53 & 3349 & 60.73 & 3362 & 58.79 & 3701 & 59.05 \\
\hline Squamous Cell Carcinoma , Nos & 766 & 20.43 & 941 & 20.72 & 1194 & 22.44 & 1232 & 22.34 & 1337 & 23.38 & 1319 & 21.04 \\
\hline Malignant Melanoma, Nos & 71 & 1.89 & 122 & 2.69 & 134 & 2.52 & 112 & 2.03 & 145 & 2.54 & 154 & 2.46 \\
\hline Basosquamous Carcinoma & 75 & 2.00 & 73 & 1.61 & 88 & 1.65 & 111 & 2.01 & 118 & 2.06 & 102 & 1.63 \\
\hline
\end{tabular}

center report of health deputy for Iran during a 6-year period (2003 - 2008). skin cancer was defined as icd-o c16 (Fritz, 2000). This study survey basal cell carcinoma nos, squamous cell carcinoma nos, malignant melanoma nos \& basosquamous carcinoma morphology.

\section{Statistical analysis}

Age-standardized rates of cancer incidence were calculated by the direct standardization method, using the world standard population as a reference. To describe incidence time trends, we carried out joinpoint regression analysis using the software Joinpoint Regression Program, Version 4.1.1.1 October 2014. As well to evaluate the morphological changes, were obtained the percentage allocated for kind of morphological types. So to analysis morphology change percentage trends for six year, we carried out joinpoint regression analysis using the software Joinpoint Regression Program. The analysis included logarithmic transformation of the rates, standard error, maximum number of one joinpoints, and minimum of six years between zero joinpoints. All other program parameters were set to default values. The aim of the approach is to identify possible joinpoints where a significant change in the trend occurs. In this study 0 joinpiont (Full model) was a significant model. The final model selected was the most parsimonious of these, with the estimated annual percent change (APC) based on the trend within each segment. In describing trends, the terms "significant increase" or "significant decrease" signify that the slope of the trend was statistically significant $(\mathrm{P}$ $<0.05)$. All statistical tests were two sided.

\section{Results}

In this study, there were 49,740 registered skin cancer cases. Of them, 18,647 cases $(37.45 \%)$ were women, and 31,113 cases $(62.55 \%)$ men. The sex ratio (male to female) was 1.67 for the total number of cases. The most common
Table 3. Joinpoint Analyses of Cancers Percentage Allocated to the Morphology Data for Skin Cancer (2008-2003)

\begin{tabular}{lcccccc}
\hline & \multicolumn{2}{c}{ Female } & & \multicolumn{2}{c}{ Male } \\
\cline { 2 - 3 } \cline { 5 - 6 } & APC & $95 \%$ CI & & APC & $95 \%$ CI \\
\hline Basal Cell Carcinoma, Nos & $-3.1^{\wedge}$ & $-4.2--2.0$ & & $-3.5^{\wedge}$ & $-4.9--2.2$ \\
Squamous Cell Carcinoma , Nos & 1.2 & $-2.9-5.5$ & & 1.5 & $-2.0-5.0$ \\
Malignant Melanoma, Nos & $5.3^{\wedge}$ & $1.3-9.3$ & & 2.7 & $-6.9-13.3$ \\
Basosquamous Carcinoma & 4.9 & $-4.2-14.8$ & & -0.2 & $-8.7-9.0$ \\
\hline
\end{tabular}

histological type was related to the Basal cell carcinoma, NOS and Squamous cell carcinoma NOS, 32,528 cases $(65.40 \%)$ and 9,258 cases $(18.61 \%)$ respectively. Of all histological types of skin cancer, BCC and SCC included in women $70.12 \%$ and $13.25 \%$, respectively. BCC and SCC included in men $62.56 \%$ and $21.82 \%$ of all histological types, respectively. The number of cases and histology studied was more in men than women over the years. The chi-square test showed statistically significant differences between men and women according to the histology $(\mathrm{p}=0.001)$.

\section{Epidemiological Trend}

Standardized Incidence Rate (ASR) (per 100,000) increased from 10.05 in 2003 to 15.57 in 2008 in women. ASR (per 100,000) also increased from 13.89 in 2003 to 22.62 in 2008 in men. Results of Joinpoint analysis revealed that there was a significant increasing trend of ASIR in both sexes (Table 1).

\section{The morphological trend}

Over the years studied, the percentage allocated to each of histology (MALIGNANT MELANOMA NOS \& BASAL CELL, SQUAMOUS CELL CARCINOMA NOS, and MALIGNANT MELANOMA NOS \& BASOSQUAMOUS CARCINOMA) was different. The percentage assigned to histology of BCC reduced from $71.66 \%$ in 2003 to $61.62 \%$ in 2008 (Table2). 
Results of Joinpoint analysis for the percentage allocated to histology showed a significant decline in both sexes for BASAL CELL CARCINOMA NOS. The percentage allocated to other histological studied was rising, except BASOSQUAMOUS CARCINOMA with the almost constant trend (Table3).

\section{Discussion}

Our findings indicated that the trend of skin cancer incidence is increasing. According to morphology, the incidence of $\mathrm{BCC}$ had a declining trend, while MELANOMA NOS \& BASAL CELL were increasing. BASOSQUAMOUS CARCINOMA in women was increasing, but in men was decreasing. Another study conducted in Italy also showed an increasing trend of skin cancer incidence(Group, 2009). Other studies also confirmed our results (Stang et al., 2006; Hussain et al., 2010). Increasing global incidence of skin cancer may be due to several factors, including climate change, environmental factors, an increase of public awareness, and diagnostic advances that have occurred in the years (Abarca and Casiccia, 2002; McCarthy, 2004; Bulliard et al., 2006; Ibiebele et al., 2007).

From epidemiologic aspect, the most important etiologic factor for all types of skin cancer is ultraviolet radiation (Wakeford, 2004). The incidence remarkably increases in regions near the equator

where there is the direct sunlight. The incidence of skin cancer is different in various races(Wakeford, 2004). Alexandria et al. investigated the relationship between sunlight exposure and skin cancer, and found that skin cancer incidence was 4.8 times more in people with high exposure to sunlight than others (28). Given to severe sun radiation in most seasons, and the lack of use of proper protection in outdoor in Iran, it should expect a high incidence of the disease.

Results of Joinpoint analysis for the percentage allocated to histology showed a significant decline in both sexes for BASAL CELL CARCINOMA NOS. The percentage allocated to other histological studied was rising, except BASOSQUAMOUS CARCINOMA with the almost constant trend.

Our study showed that there was a decreasing trend of BCC morphology. Martino et al. stated opposite findings. They found that the incidence in the Netherlands increased in both sexes from 1973 to 2008 (Flohil et al., 2011). Adam I also showed such an increasing trend (Adam I. Rubin et al., 2005). A study on cancer registry data in Jordan indicated that trend of BCC was increasing in men, but decreasing in women (Omari et al., 2006). These differences may be due to various geographic locations and individual genetic susceptibility.

Abdel K. Omari also declared that there was an increasing trend for SCC in Jordan from 1997 to 2001. Our study showed such similar findings (Omari et al., 2006). Leiter $\mathrm{U}$ et al. determined such an increasing trend (Leiter et al., 2014). An increase in non-melanoma skin cancer incidence may be due to ultraviolet sunlight, an Increase in outdoor activities, covering, an increase of longevity, the destruction of the ozone layer, genetics, and in some cases reducing the power of immune system Leiter et al. (2014) also showed an increase of incidence of melanoma skin cancer, similar to our study.

In summary, the incidence of skin cancer is rising in the country, especially basosquamous carcinoma and melanoma. Our finding revealed that epidemiology of skin cancer is changing in Iran. It is necessary to be planning for the control and prevention of this disease as a priority for health policy makers.

\section{References}

Abarca JF, Casiccia CC (2002). Skin cancer and ultraviolet-B radiation under the antarctic ozone hole: southern Chile, 1987-2000. Photodermatol Photoimmunol Photomed, 18, 294-302.

Adam I. Rubin, Elbert H. Chen, Ratner. aD (2005). Basal-cell carcinoma. $N$ Engl J Med, 353, 2262-9.

Almasi Z, Rafiemanesh H, Salehiniya H (2015). Epidemiology characteristics and trends of incidence and morphology of stomach cancer in iran. Asian Pac J Cancer Prev, 16, 2757-61.

Amoori N, Mirzaei M, Cheraghi M (2014). Incidence of cancers in Kuzestan province of iran: trend from 2004 to 2008. Asian Pac J Cancer Prev, 15, 8345-9.

Baldwin L, Dunn J (2013). Global controversies and advances in skin cancer. Asian Pac J Cancer Prev, 14, 2155-7.

Bulliard JL, Panizzon RG, Levi F (2006). [Melanoma prevention in Switzerland: where do we stand?]. Rev Med Suisse, 2, 1122-5.

Cihan YB, Baykan H, Kavuncuoglu E, et al (2013). Relationships between skin cancers and blood groups--link between nonmelanomas and ABO/Rh factors. Asian Pac J Cancer Prev, 14, 4199-203.

Colditz GA, Sellers TA, Trapido E (2006). Epidemiologyidentifying the causes and preventability of cancer? Nature Reviews Cancer, 6, 75-83.

Flohil SC, de Vries E, Neumann HA, et al (2011). Incidence, prevalence and future trends of primary basal cell carcinoma in the Netherlands. Acta Derm Venereol, 91, 24-30.

Fritz AG (2000). International classification of diseases for oncology: ICD-O. 2000: World Health Organization.

Group AW (2009). Italian cancer figures, report 2009: Cancer trend (1998-2005). Epidemiol Prev, 33, 1-168.

Hussain SK, Sundquist J, Hemminki K (2010). Incidence trends of squamous cell and rare skin cancers in the Swedish national cancer registry point to calendar year and agedependent increases. J Invest Dermatol, 130, 1323-8.

Ibiebele TI, van der Pols JC, Hughes MC, et al (2007). Dietary pattern in association with squamous cell carcinoma of the skin: a prospective study. Am J Clin Nutr, 85, 1401-8.

Jemal A, Center MM, DeSantis C, et al (2010). Global patterns of cancer incidence and mortality rates and trends. Cancer Epidemiol Biomarkers Prev, 19, 1893-907.

Keyghobadi N, Rafiemanesh H, Mohammadian-Hafshejani A, et al (2015). Epidemiology and trend of cancers in the province of Kerman: southeast of Iran. Asian Pac J Cancer Prev, 16, 1409-13.

Leiter U, Eigentler T, Garbe C (2014). Epidemiology of skin cancer. Adv Exp Med Biol, 810, 120-40.

McCarthy WH (2004). The Australian experience in sun protection and screening for melanoma. J Surg Oncol, 86, 236-45.

Omari AK, Khammash MR, Matalka I (2006). Skin cancer trends in northern Jordan. Int J Dermatol, 45, 384-8.

Parkin DM, Bray F, Ferlay J, et al (2005). Global cancer statistics, 
Saeid Razi et al

2002. CA Cancer J Clin, 55, 74-108.

Reynolds KD, Buller DB, Yaroch AL, et al (2006). Mediation of a middle school skin cancer prevention program. Health Psychol, 25, 616-25.

Rohani-Rasaf M, Abdollahi M, Jazayeri S, et al (2013). Correlation of cancer incidence with diet, smoking and socio- economic position across 22 districts of Tehran in 2008. Asian Pac J Cancer Prev, 14, 1669-76.

Saridi MI, Rekleiti MD, Toska AG, et al (2014). Assessing a sun protection program aimed at Greek elementary school students for malign melanoma prevention. Asian Pac J Cancer Prev, 15, 5009-18.

Stang A, Pukkala E, Sankila R, et al (2006). Time trend analysis of the skin melanoma incidence of Finland from 1953 through 2003 including 16,414 cases. Int J Cancer, 119, $380-4$.

Wakeford R (2004). The cancer epidemiology of radiation. Oncogene, 23, 6404-28.

WHO. 2015. How common is skin cancer? [Online]. Available: http://www.who.int/uv/faq/skincancer/en/index1.html. 